\title{
Analysis and Optimization of Process Parameters in EDM of RENE 80 Using Taguchi Method
}

\author{
A. Sugunakar, A. Kumar and R. Markandeya
}

\begin{abstract}
The present work aims to carry out an experimental investigation into the electrical discharge machining process while machining of Nickel super alloy RENE80. Taguchi L9 orthogonal array is used to plan the experimental layout. Taguchi method is used to analyze the effect of each process parameter such as peak current, pulse on time and pulse off time on chosen machining characteristics namely material removal rate (MRR) and surface roughness (SR) and also to predict the optimal combination of process parameters to get maximum material removal rate and minimum surface roughness separately. Further analysis of variance has been done to identify the significant affect of parameters on machining characteristics. It is found that parameters peak current and pulse on time have a significant affect where as pulse off time has no significant affect on material removal rate and surface roughness. Confirmation experiments are conducted at their respective optimum parametric settings to check the predicted optimal values of performance characteristics. Then percentage errors are calculated and are 0.94 and 4.87 respectively in predicting $M R R$ and SR values.
\end{abstract}

Keywords--- Electrical Discharge Machining, Taguchi Method, Peak Current, Pulse on Time, Pulse off Time, Material Removal Rate, Surface Roughness.

\section{INTRODUCTION}

$I_{w}^{\mathrm{N}}$ $\mathrm{N}$ EDM, erosion of two electrically conductive materials will occurs by instigation of recurring and continuous spark discharges in a small gap separated them. The melting of work piece will happen when sufficient heat is generated by the each electric spark also some tool material melts. The resistance increases due to evaporation of dielectric in the arc gap till interruption of arc takes place. The current flow between electrodes produces debris which is flushed out by the fluid. This can be done continually to erode a finely controlled element that would be unattainable to machine with traditional machining methods.

However certain defects like porosity, residual stress and micro cracks in the recast layer due to enormous temperature followed by sudden cooling are usually found on the machined

A. Sugunakar, Associate Professor, Department of Mechanical Engineering, Jayamukhi Institute of Technological Sciences, Warangal, T.S, India.E-mail: sugunakar.amireddy@gmail.com

A. Kumar, Associate Professor, Department Mechanical Engineering, National Institute of Technology, Warangal, T.S, India. E-mail:adepu_kumar7@yahoo.co.in

R. Markandeya, Professor, Department of Metallurgical Engineering, Jawaharlal Nehru Technological University, Hyderabad, India. E-mail:marksravvala@yahoo.co.in

DOI: 10.9756/BIJIEMS.10502 surface. Rajmohan T. et al [1] reported the electrical discharge machining parameters effect such as pulse on time, pulse off time and current on MRR of 304 stainless steel using Taguchi method. They found that maximum MRR can be achieved with different combinations of EDM process parameters. They also noticed that the most significant parameters were current and pulse off time for MRR. They also mention that the optimum cutting parameters can be achieved with minimum number of trails. They opted taguchi method which is efficient methodology to find the optimum process parameters. P.M. George et al [2] worked on the EDM machining of carboncarbon composite by using a taguchi approach. In this their aim was to derive the optimal setting of the process parameters on the electro-discharge machining (EDM). Qualitek-4 software was used to apply taguchi method. It has been shown that significant improvement in the response parameters such as MRR, SR etc. can be attained with combination of machining parameters at their optimum levels.

Beri et al [3] performed experimental study to evaluate surface roughness of Inconel 718 alloy during electrical discharge machining with powder metallurgy processed electrodes. They investigated process parameters were polarity, electrode type, peak current, pulse on time, duty cycle, gap voltage, retract distance and flushing pressure. To plan and design experiments, standard $\mathrm{L}_{36}$ orthogonal array based on Taguchi methodology was applied. The data was analyzed statistically using analysis of variance (ANOVA). Kamaljit Singh, C S Karla et al. [4] carried out experimental investigation of machining of OHNS Die steel by EDM process. They were chosen the input process parameters as peak current, pulse on time, voltage gap and flushing pressure. To optimize the machining parameters, Taguchi and ANOVA methods were used. From the experiments, it was observed that current has the significant effect on the material removal rate and flushing pressure has the major effect on the hardness of OHNS steel.

Prof. D.V.Ghewade et al. [5] have studied the effect of various process parameters like peak current, gap voltage, duty cycle and pulse on time on Inconel 718 . To analyze the effect of machining parameters on MRR, EWR, Radial Overcut and Taper Angle, Taguchi method was used. They were noticed that the MRR mainly affected by peak current and gap voltage. EWR was mainly influenced by Pulse-on time and duty cycle. Peak current and duty cycle have the major effect on ROC and pulse on time (Ton) and duty cycle $(\mathrm{t})$ were main cause for the half taper angle $\left(\alpha^{\circ}\right)$. Kapil Banker et al [6] observed the parametric optimization of Electro Discharge Machine of AISI 304 Steel by using Taguchi Method. To design the experiments, Taguchi method is used with three input parameters at three levels using L9 array. 
Copper is used as tool electrode and AISI 304 steel is used as work piece. Optimization is carried out by using Taguchi method and MINITAB software. The machining parameters were current, $T_{\text {on }}, T_{\text {off }}$, Depth of cut while response parameter was material removal rate. From the experimental work, it was noticed that MRR affected mainly by the pulse-on time parameter. It has also observed that copper has higher material removal rate as compared to other material like as aluminum, gun metal, brass, etc. M. Kiyak et al [7] have studied that the effect of EDM settings on surface roughness for machining of AISI P20 tool steel. Discharge current, pulses on time and pulse pause time were the chosen parameters. They were found that with increasing of discharge current and pulse on time, SR increased and with decrease of discharge current and pulse on time and higher pulse pause time a good surface finish was attained. Lee SH et al [8] The machining of EDM will be determined mainly by electrical parameters such as current, pulse duration, voltage and material properties of work piece and electrode like melting temperature etc and also electrical and thermal conductivity as well. Gao et al [9] developed an ANN model of the EDM process and further by using GA they optimized the input process parameters. J. Jeykrishnan, et al [10] investigated to optimize the process variables of EDM by employing a traditional technique. The machining parameters chosen for optimization were pulse on time, pulse off time and current. L9 Orthogonal Array selected to examine the effect of the process variables on the performance parameter i.e. material removal rate. The experimental trials were conducted with positive polarity on AISI D2 die steel and brass chosen as an electrode material. Haron CHC et al [11] reported the influence of process parameters on tool steel using EDM. They have concluded by optimizing the different process parameters, the copper or graphite electrode (as tool) gives the maximum MRR and minimum TWR in machining of AISI 1045 tool steel. George $\mathrm{PM}$, et al [12] have studied that by optimizing the process variables like pulse current, $T_{\text {on }}$ and gap voltage of EDM, better MRR was obtained. They have also concluded that the pulse current has been the most significant parameter that effects MRR and then by the gap voltage and $\mathrm{T}$ on. Ikram A et al [13] used ANN to optimize the process parameters while varying $T_{\text {on }}, T_{\text {off }}$, wire feed velocity, wire tension, voltage and pressure. Taguchi technique used to optimize the responses like SR, MRR and kerf. They have also found out that $T_{\text {on }}$ has a significant impact on the responses. All the experiments were conducted by WEDM on D2 die steel. Thomas S et al [14] have studied the response parameters like MRR and TWR, by optimizing the input characteristics such as $T_{\text {on }}, T_{\text {off }}$ and in Powder Mixed EDM (PMEDM), it was proved that the discharge current is the most significant parameter that affects the output characteristics while machining D2 die steel, followed by $\mathrm{T}_{\text {on }}$ and $\mathrm{T}_{\text {off. }}$ Vikram Reddy $\mathrm{V}$ et al [15] investigated the electrical discharge machining process during machining of precipitation hardened stainless steel PH17-4. Taguchi method was used to design the experimental layout, to analyze the effect of combination of process parameters on machining characteristics and to predict the optimal choice for combination EDM process parameters such as peak current, pulse on time and pulse off time that gives optimal process performance characteristics such as material removal rate, surface roughness, tool wear rate and surface hardness. Uyyala S.B et al [16] obtained optimal process parameter combination during EDM of RENE 80 alloy.

It is observed from the literature that, no extensive work has been reported so far in the area of EDM of Nickel alloy RENE80 with electrolyte copper as electrode and EDM oil (SAE450) as dielectric fluid.

The aim of the present work is to find the effect of process parameters such as peak current, pulse on time and pulse off time. Also find their significance on chosen machining characteristics namely MRR and SR. Then the optimal combination of process parameters is obtained for maximum MRR, and minimum SR separately using Taguchi method.

\section{EXPerimental SETUP, Procedure AND EQUiPMENT}

Experiments were conducted using Nickel alloy RENE80 as work material and is cut into the sample pieces dimensions of $70 \times 35 \times 4 \mathrm{~mm}$ with help of wire cut EDM process. The chemical composition of the Nickel alloy RENE80 is presented in Table 1.

Table 1: Elemental Composition of RENE 80 Nickel Super

\begin{tabular}{|c|c|}
\hline \multicolumn{2}{|c|}{ Alloy (wt \%) } \\
\hline Element & Weight \% \\
\hline $\mathrm{Al}$ & $5-6$ \\
\hline $\mathrm{Cr}$ & $9.5-12$ \\
\hline $\mathrm{Ti}$ & $2.5-3.2$ \\
\hline $\mathrm{C}$ & $0.13-0.2$ \\
\hline Mo & $3.5-4.8$ \\
\hline $\mathrm{W}$ & $4.5-5.5$ \\
\hline Co & $4-4.5$ \\
\hline $\mathrm{B}$ & $0.02 \max$ \\
\hline $\mathrm{Ce}$ & $0.015 \mathrm{max}$ \\
\hline $\mathrm{Si}$ & $<0.4$ \\
\hline Mn & $<0.4$ \\
\hline $\mathrm{Fe}$ & $0.5 \max$ \\
\hline $\mathrm{Ni}$ & Balance \\
\hline
\end{tabular}

Table 2: Mechanical and Physical Properties of RENE 80 Nickel Alloy

\begin{tabular}{|l|l|}
\hline \multicolumn{1}{|c|}{ Work Material } & \multicolumn{1}{|c|}{$\begin{array}{c}\text { RENE 80 Nickel } \\
\text { Super Alloy }\end{array}$} \\
\hline Hardness (HRC) & $43-45$ \\
\hline $\begin{array}{l}\text { Ultimate tensile strength } \\
\left(\mathrm{Kg} / \mathrm{mm}^{2}\right)\end{array}$ & 85 \\
\hline Electrical resistivity $\mathrm{n} \Omega$ & 1300 \\
\hline $\begin{array}{l}\text { Thermal conductivity } \\
\left(\mathrm{W} / \mathrm{m}^{\circ} \mathrm{K}\right)\end{array}$ & 11.5 \\
\hline Melting range $\left({ }^{\circ} \mathrm{C}\right)$ & $1320-1380$ \\
\hline Density $\left(\mathrm{g} / \mathrm{cm}^{3}\right)$ & 8.16 \\
\hline Elongation $\%$ & 3 \\
\hline Reduction in Area $\%$ & $5-7$ \\
\hline Creep strength $\left({ }^{\circ} \mathrm{C}\right)$ & 975 \\
\hline Creep rupture $\left(\mathrm{Kg} / \mathrm{mm}^{2}\right)$ & 25 \\
\hline
\end{tabular}


Table 3: Physical Properties of Electrolyte Copper

\begin{tabular}{|l|l|}
\hline Specific capacity & $383\left(\mathrm{~J} / \mathrm{kg}^{\circ} \mathrm{C}\right)$ \\
\hline Density & $8.95\left(\mathrm{~g} / \mathrm{cm}^{3}\right)$ \\
\hline Melting point & $1083^{\circ} \mathrm{C}$ \\
\hline Thermal conductivity & $394\left(\mathrm{~W} / \mathrm{m}^{\circ} \mathrm{C}\right)$ \\
\hline Electrical resistivity & $1.673 \times 10^{-8} \Omega \mathrm{m}$ \\
\hline
\end{tabular}

The mechanical and physical properties of Nickel alloy RENE80are shown in Table 2. The electrolyte copper of diameter $014 \mathrm{~mm}$ is chosen as tool material for machining Nickel alloy RENE80 and its physical properties are shown in the Table 3. Commercial EDM oil grade SAE450 is used as the dielectric fluid to conduct all the experiments. All the experiments are conducted on die sinking EDM machine of FORMATICS 50 model which is equipped with ELECTRONICA PRS 20 controller. For selecting the range of input factors trial experiments were conducted. The selected process parameters and their corresponding levels for this experimentation are shown in the Table 4 . Table 5 represents the machining conditions. Taguchi L9 Orthogonal array is selected for planning experiments and is shown Table 6. A total number of 9 experimental runs are conducted and each experimental run are repeated three times. Machining time was chosen for conducting each experiment is 3min. Both work pieces and electrodes are cleaned and polished before machining,. The Taguchi method uses signal to noise $(\mathrm{S} / \mathrm{N})$ ratio to measure the deviation of performance characteristics from the desired values. These are three categories of $\mathrm{S} / \mathrm{N}$ ratios depending on the types of characteristics like higher-isthe-best (HB), lower-is-the-best (LB) and nominal is the best (NB). MINITAB16 software was used to analyze the experimental data. For weighing the work pieces and electrodes before and after machining a digital weighing balance (citizen) capacity up to $300 \mathrm{~g}$ with a resolution of $0.1 \mathrm{mg}$ was used.Then the MRR is calculated using equation (1).

$$
\operatorname{MRR}\left(\mathrm{mm}^{3} / \min \right)=\frac{\Delta W}{\rho_{w} \times t}
$$

Where $\Delta W$ is the weight difference of work piece before and after machining $(\mathrm{g}), \rho_{\mathrm{w}}$ is density of work material $\left(\mathrm{g} / \mathrm{mm}^{3}\right)$, and $t$ is machining time in minutes. Surface roughness (SR) on machined work surfaces are measured using Talysurf surface roughness tester. The SR is represented by the center line average method (Ra). Roughness measurements are carried out in on machined surface with sampling length of $0.8 \mathrm{~mm}$ and are repeated three times and average values are calculated.

Table 4: Working Range of the Process Parameters and their Levels

\begin{tabular}{|l|l|l|l|l|l|}
\hline \multicolumn{1}{|c|}{ Parameter } & Symbol & Unit & Levell & Level2 & Level3 \\
\hline Peak current, $\mathrm{I}$ & $\mathrm{A}$ & Amps & 10 & 15 & 20 \\
\hline Pulse on time, $\mathrm{T}_{\text {on }}$ & $\mathrm{B}$ & $\mu \mathrm{s}$ & 25 & 45 & 65 \\
\hline Pulse off time, $\mathrm{T}_{\text {off }}$ & $\mathrm{C}$ & $\mu \mathrm{s}$ & 24 & 36 & 48 \\
\hline
\end{tabular}

Table 5: Machining Conditions

\begin{tabular}{|l|l|}
\hline Working conditions & \multicolumn{1}{|c|}{ Description } \\
\hline Work piece & $\begin{array}{l}\text { RENE80 Nickel super alloy } \\
(70 \mathrm{~mm} \times 35 \mathrm{~mm} \times 4 \mathrm{~mm})\end{array}$ \\
\hline Electrode & Electrolyte copper $\emptyset 14 \mathrm{~mm}$ \\
\hline Dielectric & Commercial EDM Oil grade SAE 450 \\
\hline Flushing & Side flushing with pressure $0.5 \mathrm{MPa}$ \\
\hline Polarity & positive \\
\hline Supply voltage & $240 \mathrm{~V}$ \\
\hline Machining time & 3 minutes \\
\hline
\end{tabular}

Table 6: Experimental Layout Using an $\mathrm{L}_{9}\left(3^{4}\right) \mathrm{OA}$

\begin{tabular}{|c|c|c|c|c|}
\hline \multirow{3}{*}{$\begin{array}{l}\text { Sr. } \\
\text { No. }\end{array}$} & \multicolumn{4}{|c|}{ Process parameters } \\
\hline & $A$ & $B$ & $C$ & $D$ \\
\hline & Peak current & Pulse on time & Pulse off time & Dummy \\
\hline 1 & 1 & 1 & 1 & 1 \\
\hline 2 & 1 & 2 & 2 & 2 \\
\hline 3 & 1 & 3 & 3 & 3 \\
\hline 4 & 2 & 1 & 2 & 3 \\
\hline 5 & 2 & 2 & 3 & 1 \\
\hline 6 & 2 & 3 & 1 & 2 \\
\hline 7 & 3 & 1 & 3 & 2 \\
\hline 8 & 3 & 2 & 1 & 3 \\
\hline 9 & 3 & 3 & 2 & 1 \\
\hline
\end{tabular}

\section{RESUltS AND DisCUSSION}

It is possible to sort out each process parameter on response at different levels since the experiments are designed in orthogonal nature. The raw data of various responses are collected after conducting experiments are transferred in to their respective $\mathrm{S} / \mathrm{N}$ ratio values.

\section{A. Effect of Parameters on Material Removal Rate}

The average values of MRR and respective $\mathrm{S} / \mathrm{N}$ ratio values are shown in Table 7. Figure 1 presents main effects plot for means of MRR. Figure 2 shows main effects plot for $\mathrm{S} / \mathrm{N}$ ratios of MRR. A main effects plot is a plot of the means at each level of a factor. One can use these plots to compare the magnitudes of the various main effects and compare the relative strengths of the effects across factors. However it is important to proceed to evaluate significance by looking at the effects in the analysis of variance Table. It is observed from the Figures $1 \& 2$ that MRR increases noticebly with increasing in peak current values from 10A to 20A. The peak current directly effects the spark energy available in the inter electrode gap. The increase in peak current causes increase in discharge energy resulting into higher current density that quickly over heats the work piece that causes increasing in MRR at higher peak current conditions. Also it is observed that the MRR increases with increasing in pulse on time. The spark energy in the plasma channel and the phase of transferring this energy in to the electrodes increases with increasing in pulse on time. This occurrence makes formation of bigger molten material crater on the work material that resulting into increase in MRR. However another observation is that MRR increases slightly with increasing in pulse off time. 
Table 7: Experimental Data of MRR and Corresponding S/N Ratios

\begin{tabular}{|l|l|l|l|l|l|}
\hline \multirow{2}{*}{$\begin{array}{c}\text { Exp } \\
\text { No }\end{array}$} & \multicolumn{3}{|c|}{ Process Parameters } & \multicolumn{2}{c|}{ Response MRR } \\
\cline { 2 - 6 } & $\mathrm{I}(\mathrm{A})$ & Ton $(\mu \mathrm{s})$ & Toff $(\mu \mathrm{s})$ & Means $\left(\mathrm{mm}^{3} / \mathrm{min}\right)$ & S/N Ratio(dB) \\
\hline 1 & 10 & 25 & 24 & 7.93 & 17.9855 \\
\hline 2 & 10 & 45 & 36 & 9.20 & 19.2758 \\
\hline 3 & 10 & 65 & 48 & 12.08 & 21.6413 \\
\hline 4 & 15 & 25 & 36 & 16.65 & 24.4283 \\
\hline 5 & 15 & 45 & 48 & 18.98 & 25.5659 \\
\hline 6 & 15 & 65 & 24 & 21.56 & 26.6730 \\
\hline 7 & 20 & 25 & 48 & 22.94 & 27.2119 \\
\hline 8 & 20 & 45 & 24 & 21.62 & 26.6971 \\
\hline 9 & 20 & 65 & 36 & 24.18 & 27.6691 \\
\hline
\end{tabular}

Table 8 shows response Table for means of MRR. Table 9 presents response Table for $\mathrm{S} / \mathrm{N}$ ratios for MRR. This response Table presents the effects of various input factors on MRR. Higher the slope in the main effects plot corresponding values of $\Delta$ is higher in the response Table. The rank represents directly the level of effect of input based on the values of $\Delta$. Here according to ranks, the effects of various input factors on MRR in sequence are peak current, pulse on time and pulse off time.

That means peak current affects the MRR at highest level and pulse off time at lowest level. Further ANOVA of the data at $95 \%$ confidence level is presented in Table 10 reveals that peak current, and pulse on time, are significant factors affecting the MRR since respective $\mathrm{F}$ values are higher than the $F_{c r}$. This analysis is acceptable since corresponding $\mathrm{p}$ values are small and also pulse off time has no significant effect on SR.

Since it is always desirable to maximize the MRR larger the better option is selected. Figure 2 suggested that when peak current is at 20A (level 3), pulse on time is at $65 \mu$ s (level 3 ) and pulse off time is at $48 \mu$ s (level 3), provide maximum MRR from the work surface. MRR is calculated at its optimal parameter setting and its value is $25.71 \mathrm{~mm}^{3} / \mathrm{min}$ and corresponding $\mathrm{S} / \mathrm{N}$ ratio is 29.07 .

Table 8: Response Table for Means of MRR

\begin{tabular}{|l|l|l|l|}
\hline \multicolumn{1}{|c|}{ Level } & \multicolumn{1}{c|}{$I$} & \multicolumn{1}{c|}{ Ton } & \multicolumn{1}{c|}{ Toff } \\
\hline 1 & 9.73 & 15.84 & 17.03 \\
\hline 2 & 19.06 & 16.60 & 16.77 \\
\hline 3 & 22.91 & 19.27 & 18.00 \\
\hline$\Delta$ (Max-Min) & 13.17 & 3.43 & 1.32 \\
\hline Rank & 1 & 2 & 3 \\
\hline
\end{tabular}

Table 9: Response Table for S/N Ratios of MRR

\begin{tabular}{|l|l|l|l|}
\hline \multicolumn{1}{|c|}{ Level } & \multicolumn{1}{c|}{ I } & \multicolumn{1}{c|}{ Ton } & \multicolumn{1}{c|}{ Toff } \\
\hline 1 & 19.63 & 23.21 & 23.79 \\
\hline 2 & 25.56 & 23.85 & 23.79 \\
\hline 3 & 27.19 & 25.33 & 24.81 \\
\hline$\Delta$ (Max-Min) & 7.56 & 2.12 & 1.02 \\
\hline Rank & 1 & 2 & 3 \\
\hline
\end{tabular}

Larger is better

Table 10: Analysis of Variance for MRR

\begin{tabular}{|l|l|r|c|c|c|c|}
\hline source & DOF & \multicolumn{1}{c|}{ Seq SS } & \multicolumn{1}{c|}{ Adj SS } & Adj MS & $F$ & $P$ \\
\hline $\mathrm{I}$ & 2 & 275.434 & 290.446 & 137.717 & 133.40 & 0.007 \\
\hline $\mathrm{T}_{\text {on }}$ & 2 & 19.512 & 25.134 & 9.756 & 9.45 & 0.096 \\
\hline $\mathrm{T}_{\text {off }}$ & 2 & 2.809 & 1.731 & 1.404 & 1.36 & 0.424 \\
\hline Error & 2 & 2.065 & 1.898 & 1.032 & & \\
\hline Total & 8 & 299.819 & & & & \\
\hline
\end{tabular}

$\mathrm{S}=1.01604 \quad \mathrm{R}^{2}=99.31 \% \mathrm{R}^{2}(\mathrm{adj})=97.25 \%$

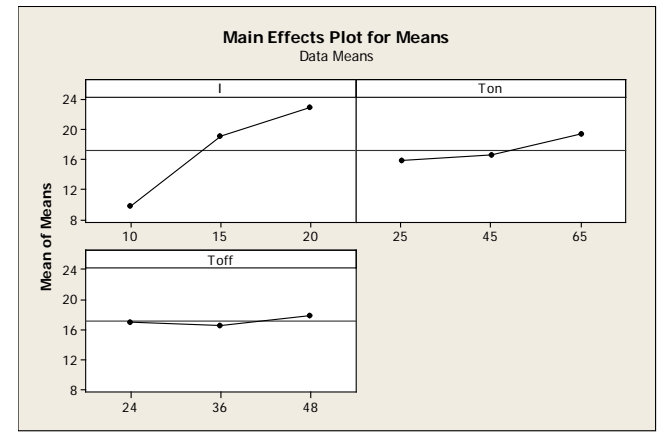

Figure 1: Main Effects Plots for Means of MRR

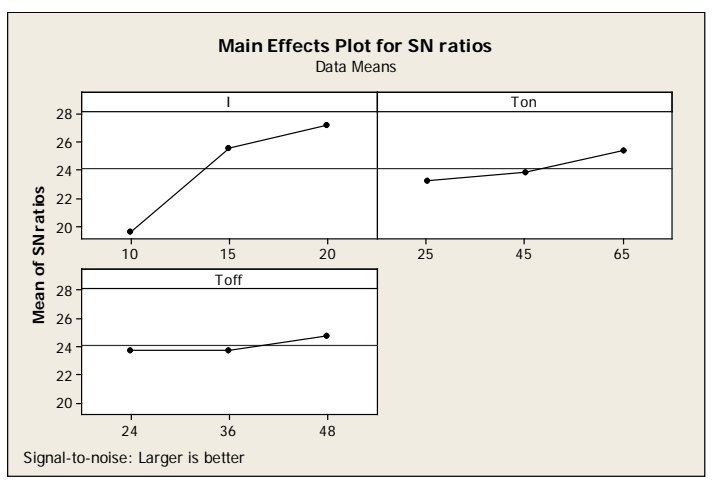

Figure 2: Main Effects Plots for S/N Ratios of MRR

\section{B. Effect of Parameters on Surface Roughness}

The average values of SR for each trial and their respective $\mathrm{S} / \mathrm{N}$ ratio values are presented in Table 11. Figure 3 presents main effects plot for means of SR. Figure 4 shows main effects plot for $\mathrm{S} / \mathrm{N}$ ratios of $\mathrm{SR}$.

Table 11: Experimental Data of SR and Corresponding S/N Ratios

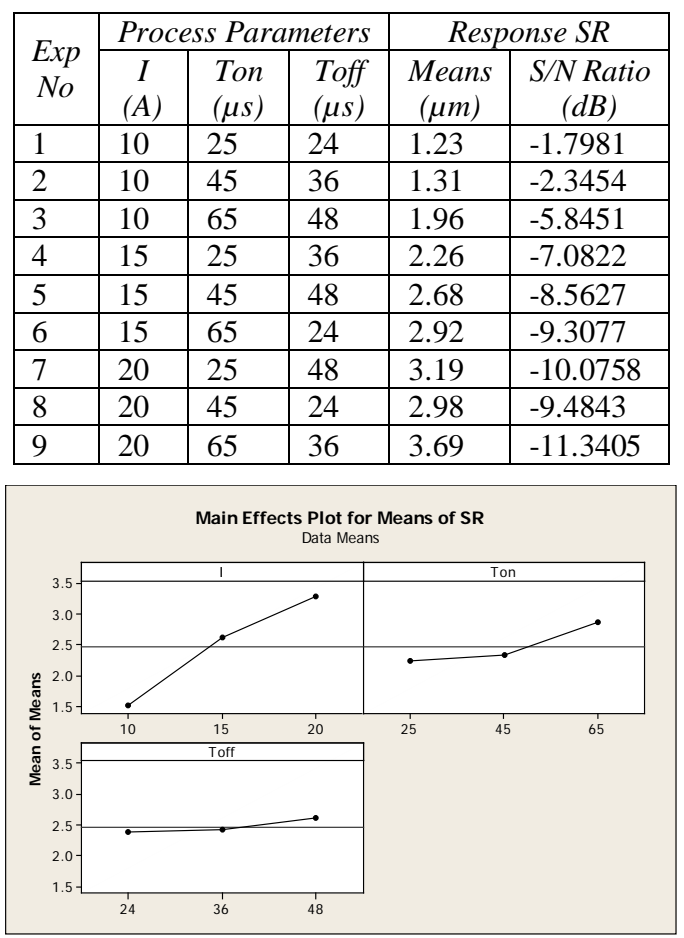

Figure 3: Effect of Process Parameters on Mean Data of SR 


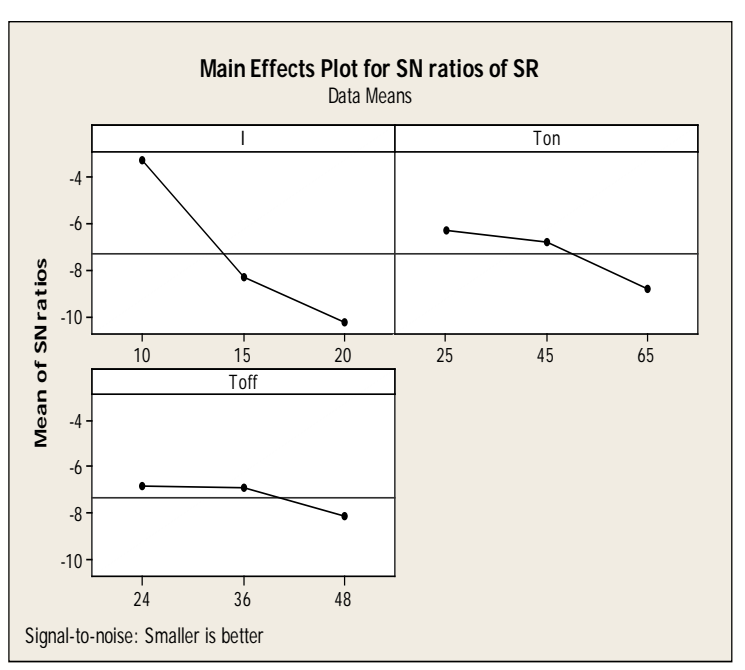

Figure 4: Effect of Process Parameters on S/N Ratio Data of SR

Further it is observed from the Figures 3 and 4 that there is increase in surface roughness with increase in peak current. This can be attributed to the fact that increase in peak current causes increase in spark energy resulting in the formation of deeper and larger craters result in increase in surface roughness. It is also noticed that surface roughness increases with the increase in pulse on time. The spark energy and time of transferring energy into the work piece increases with increase in pulse on time. This phenomenon leads to increase in formation of molten pool resulting in deeper and larger craters which again results in increase in SR.A small increase in surface roughness value is observed with the increase in pulse off time. This may be due to proper removal of debris from the discharge channel.

Table 12: Response Table for Means of SR

\begin{tabular}{|l|l|l|l|}
\hline \multicolumn{1}{|c|}{ Level } & \multicolumn{1}{c|}{ I } & \multicolumn{1}{c|}{ Ton } & \multicolumn{1}{c|}{ Toff } \\
\hline 1 & 1.500 & 2.227 & 2.377 \\
\hline 2 & 2.620 & 2.323 & 2.420 \\
\hline 3 & 3.287 & 2.857 & 2.610 \\
\hline$\Delta$ (Max-Min) & 1.787 & 0.630 & 0.233 \\
\hline Rank & 1 & 2 & 3 \\
\hline
\end{tabular}

Table 13: Response Table for Signal to Noise Ratios of SR

\begin{tabular}{|l|l|l|l|}
\hline \multicolumn{1}{|c|}{ Level } & \multicolumn{1}{c|}{ I } & \multicolumn{1}{c|}{ Ton } & \multicolumn{1}{c|}{ Toff } \\
\hline 1 & -3.330 & -6.319 & -6.863 \\
\hline 2 & -8.318 & -6.797 & -6.923 \\
\hline 3 & -10.300 & -8.831 & -8.161 \\
\hline$\Delta$ (Max-Min) & 6.971 & 2.512 & 1.298 \\
\hline Rank & 1 & 2 & 3 \\
\hline
\end{tabular}

Smaller the better

Table 12 shows response Table for means of SR. Table 13 presents response Table for $\mathrm{S} / \mathrm{N}$ ratios for $\mathrm{SR}$. This Table presents the effects of various input factors on SR. Higher the slope in the main effects plot corresponding values of $\Delta$ is higher in the response table. The rank represents directly the level of effect of input based on the values of $\Delta$. Here according to ranks, the effects of various input factors on SR in sequence of its effect are peak current, pulse on time, and pulse off time. That means peak current affects the SR at highest level and pulse off time at lowest level. Table 14 represents the ANOVA for SR at 95\% confidence level.
Table 14: Analysis of Variance for SR

\begin{tabular}{|l|l|c|c|c|r|c|}
\hline Source & DOF & Seq SS & Adj SS & Adj MS & \multicolumn{1}{|c|}{$F$} & $P$ \\
\hline $\mathrm{I}$ & 2 & 4.89102 & 4.89102 & 2.44551 & 182.80 & 0.005 \\
\hline $\mathrm{T}_{\text {on }}$ & 2 & 0.69069 & 0.69069 & 0.34534 & 25.81 & 0.037 \\
\hline $\mathrm{T}_{\text {off }}$ & 2 & 0.09242 & 0.09242 & 0.04621 & 3.45 & 0.225 \\
\hline Error & 2 & 0.02676 & 0.02676 & 0.01338 & & \\
\hline Total & 8 & 5.70089 & & & & \\
\hline
\end{tabular}

The data presented in the ANOVA reveals the significance of input parameters on SR which is as follows. The peak current, and pulse on time, are significant factors affecting the $\mathrm{SR}$ since respective $\mathrm{F}$ values are higher than the $F_{c r}$. This analysis is acceptable since corresponding $\mathrm{p}$ values are small. However pulse off time has no significant effect on SR. Since it is always desirable to minimize the SR smaller the better option is selected. From Figure 4 noticed that minimum SR value is attained when peak current at $10 \mathrm{~A}$ (level 1), pulse on

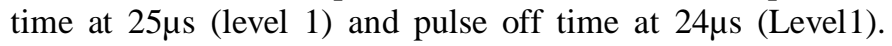
Further optimum surface roughness value is calculated as $1.17 \mu \mathrm{m}$ and corresponding $\mathrm{S} / \mathrm{N}$ ratio is -1.88 .

\section{CONFORMATION EXPERIMENTS}

To verify the predicted optimal values of responses such as MRR, and SR confirmation experiments were conducted at their optimal parametric settings. The data obtained from confirmation experiments are compared with respective predicted values.

The deviations of predicted values from experimental results are calculated as \% error and are found less than 5\% and hence they are in good agreement. Further the confirmation experimental data presented in Table 15.

$\%$ error $=\frac{\text { experimental value }- \text { predicted value }}{\text { experimental value }} \times 100$

Table15: Confirmation Experiments at Optimum Parametric Setting

\begin{tabular}{|l|c|c|l|l|l|l|l|}
\hline S.No. & \multicolumn{3}{|c|}{$\begin{array}{c}\text { Optimum } \\
\text { parameters }\end{array}$} & Response & $\begin{array}{c}\text { Experimental } \\
\text { value }\end{array}$ & $\begin{array}{c}\text { Predicted } \\
\text { value }\end{array}$ & \%error \\
\cline { 2 - 5 } & $\begin{array}{c}I \\
(\mathrm{~A})\end{array}$ & $\begin{array}{c}T_{\text {on }} \\
(\mu \mathrm{s})\end{array}$ & $\begin{array}{c}T_{\text {off }} \\
(\mu \mathrm{s})\end{array}$ & & & & \\
\hline 1 & 20 & 65 & 48 & $\begin{array}{l}\mathrm{MRR} \\
\left(\mathrm{mm}^{3} / \mathrm{min}\right)\end{array}$ & 25.47 & 25.71 & 0.94 \\
\hline 2 & 10 & 25 & 24 & $\mathrm{SR}(\mu \mathrm{m})$ & 1.23 & 1.17 & 4.87 \\
\hline
\end{tabular}

\section{CONCLUSION}

Based on the experimental results in the present study, the following conclusions are drawn:

1. Responses namely MRR and SR are increased with increasing in peak current and pulse on time. However MRR and SR increase slightly with pulse off time.

2. Further the dominant process parameters for optimum response are: $I$ is at $20 \mathrm{~A}$, Ton is at $65 \mu \mathrm{s}$ and Toff is at $48 \mu \mathrm{s}$ yield maximum MRR $\left(25.71 \mathrm{~mm}^{3} / \mathrm{min}\right)$. $I$ is at 10A, Ton is at $25 \mu \mathrm{s}$ and Toff is at $24 \mu \mathrm{s}$ yield minimum SR $(1.17 \mu \mathrm{m})$. Confirmation experiments were conducted at respective optimal parametric settings to verify predicted optimum values. The corresponding \% error values are less than 5\% 
3. Peak current and pulse on time are significant parameters affecting MRR and SR. While pulse off time has no significant affect on MRR and SR.

\section{REFERENCES}

[1] T. Rajmohan, R. Prabhu, G. Subba Rao and K. Palanikumar, "Optimization of machining parameters in Elecrical Discharge Machining (EDM) of 304 stainless steel”, Elsevier Procedia Engineering, Vol. 38, Pp. 1030-1036, 2012.

[2] P.M. George, B.K. Raghunathb, L.M. Manochac and M.W. Ashish, "EDM machining of carbon-carbon composite-a taguchi approach", Elsevier, Pp. 66-71, 2003.

[3] N. Beri, S. Maheshwari and C. Sharma, "Evaluation of surface quality during electrical discharge machining of Inconel 718 with powder metallurgy electrodes”, Advanced Materials Research. Trans Tech Publications, Vol. 410, Pp. 245-248, 2012.

[4] K. Singh and C.S. Kalra, "An experimental investigation: machining of OHNS steel by EDM”, Delta, Vol. 2, No. 6, Pp. 39-42, 2013.

[5] D. Ghewade and M.S. Nipanikar, "Experimental study of electro discharge machining for Inconel material”, Journal of Engineering Research and Studies E-ISSN, Vol. 976, Pp. 7916, 2011.

[6] K. Banker, U. Prajapati, J. Prajapati and P. Modi, "Parameter optimization of electro discharge machine of AISI 304 steel by using taguchi method", International Journal of Application or Innovation in Engineering \& Management, Vol. 3, No. 8, Pp. 20-24, 2014.

[7] M. Kiyak and O. Cakir, "Examination of machining parameters on surface roughness in EDM of tool steel”, Journal of Materials Processing Technology, Vol. 19, Pp. 141-144, 2007.

[8] S.H. Lee and X.P. Li, "Study of the effect of machining parameters on the machining characteristics in electrical discharge machining of tungsten carbide", Journal of materials processing Technology, Vol. 115, No. 3, Pp. 344-358. 2001

[9] Q. Gao, Q.H. Zhang, S.P. Su and J.H. Zhang, "Parameter optimization model in electrical discharge machining process”, Journal of Zhejiang University-Science A, Vol. 9, No. 1, Pp. 104-108, 2008.

[10] J. Jeykrishnan, B.V. Ramnath, A.J. Felix, C.R. Pernesh and S. Kalaiyarasan, "Parameter optimization of electro-discharge machining (EDM) in AISI D2 die steel using Taguchi technique”, Indian journal of science and technology, Vol. 9, No. 43, 2016.

[11] C.H.C. Haron, J.A. Ghani, Y. Burhnuddin, Y.K. Seong and C.Y. Sweez, "Investigation on the influence of machining parameters when machine tool steel using EDM", Journal of Materials Processing Technology, Vol. 116, No. 1, Pp. 84-7, 2001.

[12] P.M. George, P.K. Ragunath, L.M. Manocha and A.M. Warrier, "EDM machining of carbon-carbon composite a Taguchi approach", Journal of Materials Processing Technology, Vol. 145, No. 1, Pp. 66-71, 2004.

[13] A. Ikram, N.A. Mufti, M.Q. Saleem and A.Z. Khan, "Parametric optimization of surface roughness, kerf and MRR in WEDM using Taguchi Design of Experiment”, International Journal of Advanced Manufacturing Technology, Vol. 27, No. 7, Pp. 2133- 41, 2013.

[14] S. Thomas, S. Ramesh and J. Jeykrishnan, "Parametric optimization of powder mixed electro discharge machining using Taguchi technique", International Journal of Latest Trends in Engineering and Technology, Vol. 7, No. 3, Pp. 1-12, 2016.

[15] V. Vikram Reddy, A. Kumar and P. Madar Valli, "Influence of process parameters on characteristics of electrical discharge machining of PH174 stainless steel”, Journal of Advanced Manufacturing systems, Vol. 14, No. 3, Pp. 189-202, 2015.

[16] S.B. Uyyala, A. Kumar and A.G. Krishna, "Performance analysis of electrical discharge machining parameters on RENE 80 nickel super alloy using statistical tools”, International Journal of Machining and Machinability of Materials, Vol. 15, No. 3/4, Pp. 212-234, 2014. 